\title{
ENTRE NÓS, EM DEFESA DE UMA ESCOLA
}

\author{
AMONG US, IN DEFENSE OF A SCHOOL
}

ENTRE NOSOTROS, EN DEFENSA DE UNA ESCUELA

Walter Omar Kohan ${ }^{1}$

\section{RESUMO}

Neste texto, proponho-me a esclarecer alguns aspectos da defesa da escola realizada por J. Masschelein e M. Simons em sua obra Em defesa da escola, bem como incorporar alguns elementos próprios de uma outra tradição - a escola popular de Simón Rodríguez - com o intuito mais amplo de aprofundar o debate desencadeado pelas teses dos autores belgas e torná-las ainda mais ressoantes para o contexto brasileiro. Para isso, na "Apresentação", situo a importância do debate no atual cenário da educação nacional. Na seção seguinte, "Em defesa da escola", apresento as teses principais do livro, assim como o caráter específico da proposta dos autores belgas sobre as relações entre escola e política. Já na seção "Em defesa da defesa: uma visão (a)política?", contextualizo os principais autores que influenciaram a obra e detalho a maneira específica como ela se situaria em oposição a propostas como "Escola sem Partido", as quais sintetizam a atual política educativa do governo brasileiro. Em "A invenção de uma escola entre nós", introduzo alguns elementos da proposta de escola popular de Simón Rodríguez e, em particular, sua aposta na invenção e na atenção. Por último, em "Considerações Finais" incorporo a ideia de errância na afirmação de uma escola outra entre nós, inspirado em Le Tiers-Instruit de M. Serres.

PALAVRAS-CHAVE: Jan Masschelein. Maarten Simons. Simón Rodríguez. Escola pública. Invenção. Errância.

\begin{abstract}
In this text, I try to clarify some aspects of the defense of the school undertaken by J. Masschelein and M. Simons in In defense of the school, as well as to incorporate some elements from another tradition, the popular school of Simón Rodríguez. The broader aim is to strengthen the problematizing effects of the theses of the Belgian authors and make them even more resounding for our context. For this, in the "Presentation" I place the importance of this debate in the current scenario of Brazilian education. In "In defense of the school" I present the main theses of the book as well as the specific character of the proposal of the Belgian authors concerning the relations between school and politics. In "In defense of defense: a political vision?" । contextualize the main authors who have influenced the work of J. Masschelein and M. Simons and detail the specific way in which it would stand in opposition to proposals like "School without Party" that synthesizes the actual Education Policy of the Brazilian Government. In "The invention of a school between us" I introduce some elements of the proposal of the popular school of Simón Rodríguez, in particular its emphasis in invention and attention. Finally, in "Final Considerations" I bring the idea of "errantry" in the affirmation of a school between us inspired by M. Serres, Le Tiers-Instruit.
\end{abstract}

KEYWORDS Jan Masschelein. Maarten Simons. Simón Rodríguez. Public school. Invention. Errantry.

\footnotetext{
${ }^{1}$ Doutorado em Filosofia - Universidade Iberoamericana México - Ciudad de México - México. Graduação em Filosofia - Universidade de Buenos Aires - Buenos Aires - Argentina. Professor titular pela Universidade do Estado do Rio de Janeiro (UERJ) - Rio de Janeiro, RJ - Brasil. E-mail: wokohan@gmail.com.
}

(C) ETD- Educação Temática Digital Campinas, SP $\quad$ v.19 n.4 $\quad$ p. 590-606 out./dez. 2017 


\section{RESUMEN}

En este texto, intento aclarar algunos aspectos de la defensa de la escuela emprendida por J. Masschelein y M. Simons en En defensa de la escuela, así como incorporar algunos elementos de otra tradición, la escuela popular de Simón Rodríguez. El sentido más amplio es fortalecer el efecto desestabilizador del trabajo de los autores belgas en el campo de las ideas pedagógicas y hacerlas aún más resonantes para nuestro contexto. Para ello, en la "Presentación" sitúo la importancia del debate en el escenario actual de la educación brasileña. En "En defensa de la escuela" presento las tesis principales del libro estudiado, así como el carácter específico de la propuesta de los autores belgas sobre las relaciones entre escuela y política. En "En defensa de la defensa: ¿una visión política?" contextualizo a los principales autores que han influido la obra de J. Masschelein y M. Simons y detallo la manera específica en que se opondría a una propuesta como "Escola sem Partido", propuesta actual del Gobierno brasileño como parte de su Política Educativa. En "La invención de una escuela entre nosotros" introduzco algunos elementos de la propuesta de escuela popular de Simón Rodríguez, en especial su énfasis en invención y atención. Por último, en "Consideraciones Finales" incorporo la idea de "errancia", inspirado en Le Tiers-Incluit de M. Serres, para afirmar una escuela entre nosotros.

PALABRAS CLAVE: Jan Masschelein. Maarten Simons. Simón Rodríguez. Escuela pública. Invención. Errancia.

Explodir em pedaços para lançar-se a um caminho de destino incerto exige tal heroísmo que sobre todo a infância é capaz dele e é preciso, ainda, seduzi-la para que se comprometa nele. Seduzir: conduzir a outra parte. Bifurcar da condição dita natural. (...) Obrigatoriamente, bifurcar quer dizer se comprometer num caminho de travessia que conduz a um lugar ignorado. Sobre tudo: jamais tomar a rota cómoda, melhor, atravessar o rio nadando. (SERRES, 1991, p. 28-9)².

\section{APRESENTAÇÃO}

O livro Em defesa da escola de Jan Masschelein e Maarten Simons (2013) resulta polêmico e intempestivo por várias razões. Dentre elas, sinalizarei algumas. Em primeiro lugar, porque a própria defesa de uma instituição submetida tão regularmente ao ataque e ao discurso crítico, seja de corte genealógico, marxista ou qualquer outro, parece de outro tempo. A escola recebe críticas de todas as partes e em todos os sentidos, mais ainda uma escola pública como a brasileira, levando em consideração a extrema exposição a que ela está submetida aos poderes políticos, religiosos, econômicos. Assim, situamos a intempestividade do livro de Masschelein e Simons na forma de uma pergunta: depois de tudo o que sabemos sobre a instituição escolar, alguém ainda se atreve a defendê-la? E os que trabalhamos nela, seja de modo direto ou na forma de projetos de extensão e formação docente, ainda pensamos que vale a pena defendê-la? Eis, em parte, a ousadia da aposta dos autores belgas.

Em segundo lugar, Em defesa da escola apresenta certas dificuldades para precisar o estatuto epistemológico, ontológico e político da forma escolar - skholé - que ele se esforça em afirmar. É a essência da escola que os autores estão defendendo? É uma escola universal? É um modelo ou ideal de escola? É um discurso científico, próprio das ciências da

\footnotetext{
${ }^{2}$ Nesta e todos as outras citações deste livro a tradução é nossa.
}

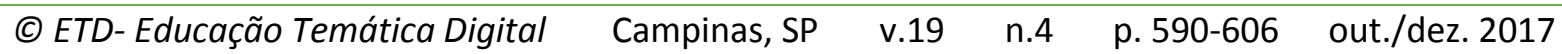


educação? É uma "nova" filosofia da escola? Em suma, qual é o estatuto epistemológico dessa escola defendida? Alguns podem rapidamente subtrair implicações filosóficas e ideológicas polêmicas do livro, em especial no atual momento da educação brasileira em que movimentos de corte ultraconservador, como a "Escola sem Partido", podem tentar fazer alguma parceria com as ideias do livro, na medida em que este afirma também uma separação entre escola e política.

Trata-se, por tanto, de um debate da maior relevância, sutileza e pertinência para a educação brasileira. Dado o momento atual do mundo, talvez não apenas para ela. Assim, neste breve texto, apenas me proponho a esclarecer alguns aspectos da defesa da escola realizada por Masschelein e Simons, bem como incorporar alguns elementos próprios de uma outra tradição escolar, a escola popular de Simón Rodríguez, com o intuito mais amplo de reforçar a defesa da escola empreendida pelos autores belgas e de tornar suas teses ainda mais ressoantes para o nosso contexto.

\title{
EM DEFESA DA ESCOLA (Masschelein; Simons)
}

\begin{abstract}
Então, a escola (como forma pedagógica) refere-se a uma associação de pessoas e coisas dispostas como uma forma de lidar com, prestar atenção a, cuidar de alguma coisa - para obter e estar em sua companhia - na qual este cuidado envolve estruturalmente uma exposição. Nesse sentido, a escola, isto é, como forma pedagógica, não é nem orientada nem domesticada por uma utopia política nem por um ideal normativo de uma pessoa, mas é em si mesma a materialização de uma crença utópica: todos podem aprender tudo. (MASSCHELEIN; SIMONS, 2016, p. 292, destaque dos autores)
\end{abstract}

Talvez seja oportuno retomar rapidamente a estrutura de Em defesa da escola, a começar pelo próprio título: trata-se de uma defesa ou apologia (esta palavra aparece mais claramente no original holandês (Apologie van de school. Leuven/Den Haag: Acco, 2012), ou seja, trata-se de uma reação às acusações que a escola, assim com a forma universal do artigo definido, recebe. Não se trata, portanto, de uma apologia desta ou daquela escola, mas da escola como tal, da escola enquanto escola. Finalmente, o subtítulo - "uma questão pública" - é muito significativo ao sugerir que a apologia oferecida é de interesse público, de todos os seres humanos. Mas também se antecipa o que a escola opera na visão dos autores: "tornar o mundo público", ou seja, a possibilidade dada às novas gerações de um novo começo.

Uma primeira questão, então, que logo se coloca é se o que Masschelein e Simons defendem é o mesmo que está sendo atacado. A resposta a essa pergunta não é simples porque, justamente, a estratégia principal dos autores belgas é deslocar o foco do campo histórico, social e cultural a uma espécie de forma originária, primordial, quase arquetípica, surgida da escola grega antiga: skholé. Eles não estudam a instituição escolar, mas

\begin{tabular}{|c|c|}
\hline (C) ETD- Educação Temática Digital & \\
\hline
\end{tabular}


defendem uma forma escolar para eles decisiva para pensar, na educação, enquanto educadores. Essa forma atravessaria, ou não, a instituição escolar e poderia, ou não, se encontrar nelas. Ou seja, pode muito bem haver instituição escolar sem a forma escolar, e também a forma escolar encontrar-se fora das instituições escolares. O que Masschelein e Simons defendem, portanto, é algo que, de certa forma, atravessaria diversos tempos e espaços, algo que persistiria através da geografia e da história como uma espécie de coração, âmago, cerne (as palavras aqui são muito difíceis) ou quintessência da escola.

A estrutura do livro contém cinco capítulos. Um primeiro no qual se sintetiza o que, para Masschelein e Simons (2013), são as principais críticas e acusações à escola: alienação, concentração de poder, corrupção, desmotivação, ineficácia, falta de empregabilidade, redundância. A estratégia dos autores não é responder tais críticas diretamente, senão de modo indireto, mostrando o que é fundamental do escolar; o que todas essas críticas parecem, em comum, desconhecer. Por exemplo, critica-se o afastamento da escola em relação ao mundo quando justamente essa separação é uma condição de possibilidade do escolar. Assim, os autores respondem as principais críticas acumuladas em torno da instituição escolar apresentando essa forma que o escolar nem sempre adquire nas instituições. No livro essas características do escolar são assim definidas: a) suspensão (na escola deixa de operar ou valer o que rege o mundo familiar e social exterior à escola); b) profanação (há na escola uma ressignificação livre e profanadora do que opera no mundo exterior; ela exige a possibilidade de renovar o que é público); c) atenção e mundo (na escola o mundo torna-se interessante e aberto para ser explorado e recriado); d) tecnologia (são as técnicas, exercícios e disciplina capazes de formar o aluno e torná-lo capaz de iniciar algo); e) igualdade (todos os alunos enquanto alunos são igualmente capazes de um novo começo do mundo); f) amor (amadorismo do professor: amor/respeito, atenção, dedicação, paixão impessoal pelo mundo e pelas novas gerações); g) preparação (na escola importa a preparação pela própria preparação, como estudo e exercício, enquanto formadora de si, sem um fim explícito ou predefinido); h) responsabilidade (a escola faz com que as coisas do mundo "falem", "tenham autoria" para os alunos).

Em conjunto, essas características apresentam a escola com um caráter radicalmente democrático, público e renovador, num sentido que os autores belgas buscam precisar: na escola se suspendem as hierarquias e desigualdades sociais; ela se dirige a todos por igual; nela, o mundo pode ser renovado pelas novas gerações. Por essa potência de desacralizar e renovar a ordem e os privilégios sociais instituídos, ela tem gerado diversas tentativas de captura dirigidas ora à escola ora ao professor. As primeiras são analisadas no terceiro capítulo do livro e classificadas em termos de: doutrinação, infantilização, pedagogização, naturalização, tecnologização, psicologização, popularização. As segundas, no capítulo quarto: profissionalização e flexibilização. No último capítulo, Masschelein e Simons traçam

\begin{tabular}{|c|c|}
\hline (C) ETD- Educação Temática Digital & \\
\hline
\end{tabular}


algumas conclusões do estudo, reafirmando o caráter democrático e comunitário da escola, no sentido de criadora de um bem comum, a partir de uma crítica à cultura escolar capitalista centrada na aprendizagem empreendedora.

Mais recentemente, após a publicação de "Em defesa da escola", em parte desenvolvendo algumas ideias apresentadas ali inicialmente, em parte respondendo a algumas críticas recebidas, Masschelein e Simons introduzem algumas variantes daquela apresentação inicial. Em particular, eles incluem outra característica como essencial do escolar, que chamam de "gramatização" (cf., por exemplo, MASSCHELEIN; SIMONS, 2016) e que diz respeito a uma caraterização da linguagem propriamente escolar. Os pedagogos belgas têm se esforçado em destacar o caráter especificamente pedagógico do seu olhar sobre a escola, como uma forma de dar voz à própria experiência de aprendizagem escolar que, desde outras áreas, como a filosofia ou as ciências sociais, é vista de modo externo e inespecífico (MASSCHELEIN; SIMONS, 2016; SIMONS; MASSCHELEIN, 2016). Ou seja, da escola tem se destacado - geralmente na forma da crítica da instituição escolar - sua dimensão filosófica, social, cultural, histórica, mas existe uma visão pedagógica primordial desconsiderada, silenciada ou desatendida, à qual eles procuram dar voz. Apresentada em linguajar foucaultiano, tratar-se-ia de uma ontologia criativa ${ }^{3}$ do presente escolar, a fim de nos re-familiarizar - e não nos des-familiarizar - com o que a escola torna possível (MASSCHELEIN; SIMONS, 2016, p. 293).

\title{
EM DEFESA DA DEFESA: UMA VISÃO (A)POLÍTICA?
}

\begin{abstract}
E, claro, a nossa defesa da escola não ignorava as críticas devastadoras e profundas da escola em tanto algo como uma prisão, subjugante, opressivo, colonizador, máquina bancária ou como uma tecnologia ultrapassada de poder. No entanto, não queríamos sustentar que a escola, como a conhecemos hoje, entanto uma instituição ou organização, é escolástica no sentido que tentamos elaborar. Porém, acreditávamos e ainda acreditamos que vale a pena tentar desterrar as operações radicais e revolucionárias da escola como um arranjo pedagógico muito particular e prático, que surgiu na Grécia, de tornar as coisas públicas e de reunir pessoas e mundo (MASSCHELEIN; SIMONS, 2016, p. 292, destaque dos autores).
\end{abstract}

No Brasil, o trabalho de J. Masschelein e M. Simons tem recebido algumas críticas pela separação que operariam entre escola e política, o que os aproximaria de propostas como a "Escola sem Partido", de caráter claramente regressivo e conservador para a educação pública brasileira. Considero essa aproximação um equívoco por, pelo menos,

\footnotetext{
3 A expressão está inspirada na ontologia crítica de M. Foucault. Masschelein e Simons resgatam o sentido de "crítica" no último Foucault, não como um julgamento, mas como uma atitude em relação ao presente, uma ex-posição que supõe uma suspensão do juízo que torne possíveis outras experiências. Cf. Masschelein; Simons, 2014. Eles estão mais interessados em lembrar o que a escola torna possível do que em denunciar o que ela impossibilita.
}

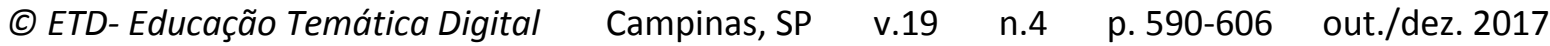


duas razões principais. A primeira diz respeito aos sentidos que, em um e outro caso, tem o termo "político". Para Masschelein e Simons, a experiência escolar não é política por que não fazemos nenhum bem a ela se a colocarmos a serviço de um fim político previamente estabelecido por quem quer que seja. É nesse sentido que a escola enquanto escola não é política: por que, quando opera propriamente como uma escola, ela não se submete a nenhuma política afirmada fora do próprio âmbito escolar. Mas, em outro sentido, para os autores belgas a escola enquanto escola é fortemente política numa multiplicidade de sentidos: a) porque o fato da criação de uma escola é em si próprio um ato profundamente político por parte de uma comunidade, uma sociedade, um grupo de indivíduos, ou um indivíduo, que, quando cria uma escola (que funciona enquanto escola), instaura um espaço para renovar e refazer a própria ordem social, sem ter controle ou domínio sobre essa recriação ou renovação; e b) porque a experiência escolar contém, enquanto tal, um caráter que Masschelein e Simons definem como o mais propriamente pedagógico: uma dimensão política consistente em que ela permite aos seus participantes tomar distância do mundo tal como o habitam para poder recriá-lo e renová-lo e habitá-lo de outra maneira ou habitar um outro mundo.

A segunda diferença fundamental, que afasta radicalmente as ideias de Masschelein e Simons da "Escola sem Partido", é o sentido que para ambos tem a escola e o efeito dessa despolitização da escola, que, no segundo caso, é um enfraquecimento da própria escola em função de uma lógica externa à qual ela indiretamente se submeteria. No caso dos autores belgas, trata-se do fortalecimento da escola como espaço autônomo para justamente empoderar esse espaço e, com ele, a nova geração que, nele, poderá recriar o mundo. No fundo, trata-se de duas ideias diametralmente opostas de escola: uma de total incapacidade e impotência frente à outra com uma incondicional ou irrestrita potencia de renovação e transformação do mundo. De um lado, a ausência da política pela impotência com que é concebida a instituição que a acolheria; de outro, a ausência da velha política na instituição dos velhos como possibilidade da afirmação, nela, de uma nova política dos novos.

Masschelein e Simons tomam como ponto de partida e referência a escola grega, em particular a escola de Isócrates (cf. KOHAN; MASSCHELEIN, 2014) e relacionam a ideia inspirada em J. Rancière de um ódio à democracia com um ódio à escola que derivaria de seu caráter democrático, público e renovador (MASSCHELEIN; SIMONS, 2014, p. 93), e que seria ainda maior de que o ódio à democracia na medida em que a escola seria uma invenção ainda mais radical do que a própria democracia (MASSCHELEIN; SIMONS, 2016). A "Escola sem Partido" seria então uma das formas em que se materializa esse medo à potência renovadora da escola. Os antigos gregos seriam os criadores da democracia e da

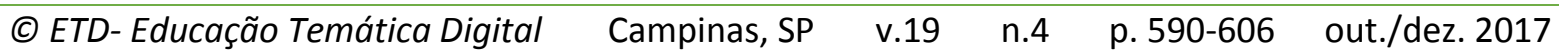


escola, skholé, tempo livre, otium, leasure (LIDDELL; SCOTT, 1966), que, para Masschelein e Simons, constitui a forma escolar por excelência, em qualquer tempo e lugar.

Em termos de referências contemporâneas, três autores certamente difíceis de classificar, mas que seguramente não são pedagogos, pelo menos não especificamente, constituem, talvez, as referências principais com que essa visão do escolar dialoga. Refirome a J. Rancière, $\mathrm{H}$. Arendt e $\mathrm{M}$. Foucault, três pensadores que igualmente resistem a ser chamados de filósofos (ou filósofa), mas que ao mesmo tempo recriam um modo particular de exercer a filosofia, certamente pouco condizente com o modo dominante de exercer a academia filosófica. Poderíamos afirmar que Masschelein e Simons compartilham com todos esses autores uma visão crítica do modo de exercer a filosofia no mundo acadêmico e uma certa recriação dela, embora os autores belgas não aceitariam que se tratasse propriamente de filosofia, e sim de pedagogia.

De J. Rancière, Masschelein e Simons tomam emprestada a ideia da igualdade das inteligências como princípio, da democracia (grega) como forma política por excelência, e da skholé como forma do escolar e locus eminente da igualdade. Efetivamente, se em O mestre ignorante (RANCIÈRE, 2002) o argelino apresenta a escola apenas desde uma lógica institucional indiferenciada a respeito de outras instituições como os partidos políticos, os exércitos ou os hospitais, e incompatível com a igualdade das inteligências, princípio necessário da emancipação, no texto École, production, égalité (RANCIÈRE, 1988), publicado apenas um ano depois da primeira edição daquele, a escola é afirmada já não como instituição, mas enquanto forma, como o locus por excelência da igualdade. Esse pequeno texto de Rancière, em particular a ideia da escola como forma eminente de experiência igualitária de tempo livre, espaço dissociado da experiência social do tempo, parece ter inspirado fortemente os autores belgas, os quais desdobram e aprofundam essa linha de pensamento numa direção muito diferente à do próprio Rancière, quem, por outro lado, nunca manifestou particular interesse pela cena educacional, a não ser como espaço ou situação para pensar a política. Assim, se a escola tem um lugar bastante decepcionante para pensar a política em $O$ mestre ignorante, e a emancipação ali só é possível numa relação individual de mestre - discípulo, ou seja, numa relação sem escola, a forma escolar que Rancière destaca em École, production, égalité é a base da defesa da escola elaborada por Masschelein e Simons. Afinal, $O$ mestre ignorante não é um livro sobre a escola, mas sobre uma prática política emancipadora que, emanada de uma experiência escolar, acaba encontrando na escola seu próprio obstáculo. É preciso, portanto, outra figura, outra forma do mestre emancipador, algo que os autores belgas ainda não explicitaram suficientemente.

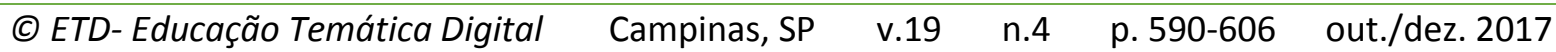


Por outro lado, é notável a presença de algumas categorias arendtianas nessa arquitetura da defesa escolar apresentada por Masschelein e Simons. Em primeiro lugar, é muito forte a educação associada à ideia de natalidade e a uma forma de resposta ao fato de que nascem seres humanos no mundo, de que chegam novos seres humanos ao mundo (ARENDT, 1977), bem como à ideia de que a educação é o campo onde se verifica nosso amor pelo mundo e pelas novas gerações, nossa responsabilidade para oferecer a elas a possibilidade de renová-lo. Em Arendt também se inspiram em relação à ideia de que o que faz um professor é colocar algo sobre a mesa e, desse modo, é do fato de oferecê-lo aos estudantes que emerge a sua autoridade e a sua responsabilidade. A autoridade diz respeito não a um exercício de poder, mas ao sentido que inaugura sua tarefa: algo com autoridade diz algo, significa, abre um sentido, fala, dá vida, aumenta o mundo, cuida dele: a partir do ato de um professor o mundo recebe um outro sentido para o aluno. Dali nasce a responsabilidade pedagógica: colocar algo do mundo sobre a mesa, oferecê-lo aos estudantes exige chamar a responsabilidade sobre isso que se lhes oferece como objeto de estudo. Também os autores belgas se inspiram na pensadora alemã ao separar educação e política, para evitar fazer da educação uma terra da ação política, a qual é reservada aos adultos. Curiosamente, como Rancière, Arendt também não é das pensadoras mais interessadas na educação e escreve relativamente pouco a respeito, apenas por que é importante para compreender a situação política do seu tempo.

Finalmente, os ecos foucaultianos são, em alguma medida, os mais difíceis de detectar, mas, em outro sentido, talvez os mais persistentes e profundos... Em particular, o último Foucault, o da Hermenêutica do Sujeito (2006), nessa visão afirmativa da disciplina na sua última leitura dos gregos, no estudo da áskesis, dos exercícios e práticas de si que permitem certa libertação das práticas de governo e um certo exercício prático da liberdade através do cuidado de si... Assim, a vida do sujeito como exercício, o trabalho sobre si de quem não quer ser governado pelo outro, aparece como o fundo sobre o qual Masschelein e Simons desenham a vida escolar, a rotina de um estudante, a experiência e o exercício do tempo livre escolar... Uma vida de exercício, de treinamento, de preparação, não para um fim exterior mas pela própria preparação, para um estar preparado; exercícios de atenção para estar atento, à espreita, uma espécie de atletismo escolar, um expor-se para estar preparado à exposição, uma vida estudantil de atleta, de experimentos e exercícios com outros, de exercícios de pensamento para pensar de outra maneira, para ver o mundo de outra maneira, para habitar e atentar para outros mundos... 


\title{
A INVENÇÃO DE UMA ESCOLA ENTRE NÓS
}

\begin{abstract}
A finalidade da instrução é o fim da instrução, ou seja, a invenção. A invenção é o único verdadeiro ato intelectual, a única ação da inteligência. O resto? Cópia, fofoca, reprodução, preguiça, convenção, batalha, sono. Apenas acorda a descoberta. Apenas a invenção prova que realmente pensamos aquilo que pensamos, qualquer que seja a coisa. Eu penso, logo invento; invento, logo penso: única evidência de que um sábio trabalha ou de que um escritor escreve. Para que trabalhar, para que escrever, de outra forma? Em outros casos, eles dormem ou brigam e mal se preparam para morrer. Repetindo. O sopro inventivo só dá a vida, porque a vida inventa. A ausência de invenção prova, por contraprova, a ausência de obra e pensamento. Quem não inventa trabalha em qualquer parte menos na inteligência. Besta. Em qualquer parte menos na vida. Morte. (SERRES, 1991, p. 147)
\end{abstract}

Na América Latina existe uma outra tradição de escola: a escola popular e, dentro dela, o venezuelano Simón Rodríguez resulta um nome singular ${ }^{4}$. Certamente não se trata de uma tradição desconectada da skholé grega, tanto que o próprio Rodríguez se refere explicitamente a ela mais de uma vez (RODRÍGUEZ, 2001). Considero que Simón Rodríguez, o mestre de Simón Bolívar, é uma figura relevante para a perspectiva de Masschelein e Simons porque foi, de fato, um professor de escola e ele próprio construiu escolas nas quais ele mesmo ensinava e vivia. Uma delas, a "Escola de Órfãos e Meninos de Marcenaria", criada em 1826 em Chuquisaca, então Capital da Bolívia, instaura na América uma experiência escolar absolutamente inédita para a época, que interrompe a ordem escolar vigente (DURÁN, 2016). Rodríguez suspende a ordem honorífica e tradicional da sociedade monárquica, segundo a qual as crianças frequentavam uma escola em função da casta à qual pertenciam, e cria uma escola, sem condições, em pé de igualdade, para todas as crianças, para além de sua cor de pele, casta, pertença cultural, sexo ou religião. Ou seja, ele abre as portas da escola para crianças brancas, negras, mestiças, indígenas, filhos de "prostitutas" e "ladrões" que, na época, eram considerados pelo conjunto da população branca espanhola ou filha de espanhóis como "carentes de alma" e "faltosos de razão". (DURÁN, 2016, p. 293). Na escola de Rodríguez, se suspendem os privilégios e hierarquias sociais; ali todos são iguais. A ameaça provocada pela escola de Chuquisaca à ordem social é tão grande que, poucos meses depois de sua criação, ela é literalmente demolida, soterrada pelas elites dominantes. Rodríguez é acusado de louco, de malversação do dinheiro público, alguém considerado sem qualquer valor, resultando submetido a todo tipo de desqualificações (RODRÍGUEZ, 2016, p. 22 ss.).

Para Rodríguez, a escola-modelo de Chuquisaca teria um impacto político inestimável na América: ela era o caminho para a conformação de uma República na qual a Gente Nova, como Rodríguez chama os originários da terra, teria uma vida digna, como não

\footnotetext{
${ }^{4}$ Algumas autoras, como A. Puiggrós, levam essa linha até Paulo Freire. Cf. PUIGGRÓS, 2005.
}

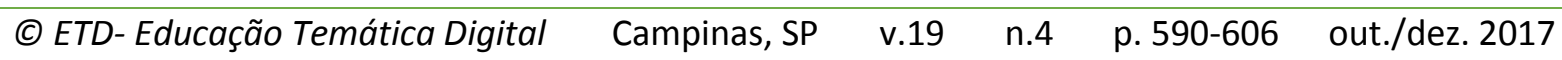


havia no regime feudal da Monarquia (RODRÍGUEZ, 2016, p. 25). Ele oferece algumas observações pontuais sobre a prática dessa escola. Tratava-se de combater a ignorância e instruir o povo inteiro para que ele possa formar sua opinião, fundamento do sistema republicano. Nela, pensar na natureza das coisas estava na base da formação, e o sentido principal dessa escola era promover espíritos pensantes e inventivos; ao contrário, quando se provoca ou permite a preguiça de pensar, estamos perante a causa da formação de indivíduos imitadores (RODRÍGUEZ, 2016, p. 19-20).

Sabemos também que nessa escola-modelo de Chuquisaca se aprendiam ofícios e se estimulava e exercitava o trabalho. Aprendia-se pela prática e pelo exercício de certas capacidades para a vida em comum. Rodríguez apresenta com muitos detalhes as condições do diretor de uma tal escola que, segundo ele afirma, "deve ter mais aptidões que o Presidente da República" (RODRÍGUEZ, 2016, p. 23). Afirma que deve estar presente na escola "com a cabeça e com as mãos", comparando seu trabalho escolar a uma "viagem em alto mar" e, dentre seus dotes pessoais principais, afirma que deve ser "desinteressado, prudente, aficionado pela invenção, despreocupado, enfim... homem do mundo..." (RODRÍGUEZ, 2016, p. 24, itálico do autor).

A invenção é uma palavra importante para Simón Rodríguez. Uma e outra vez enfatiza a importância de a América ser uma terra inventiva e não imitadora. A afirmação vale para diversos âmbitos e é particularmente fértil no campo da educação e da escola: a escola, seu diretor, o professor, o aluno, todos devem ser inventivos. Certamente, a palavra invenção está hoje na ordem do dia dos discursos pedagógicos dominantes. Ela se aproxima de outras como criação, inovação, que estão igualmente acentuadas na vulgata oficial em tempos neoliberais. A inventividade seria mais uma capacidade ou habilidade do aluno empreendedor que o tornaria mais competente para a vida social, entendida como um espaço de competitividade e meritocracia. A invenção é hoje, é verdade, parte de um discurso que submete o fazer escolar à lógica e aos interesses do capital. Vale a pena então reafirmá-la nesse contexto? Em que sentido?

Para Simón Rodríguez, a invenção parece ter uma outra posição e valor (KOHAN, 2013). De uma parte, é importante lembrar a etimologia da palavra que Rodríguez bem conhece: in-ventus, de in, 'em' e ventus, particípio passado do verbo latim venire, com o significado de 'veio', 'chegado', 'arribado', ou seja, invento literalmente significa 'que veio dentro', de modo tal que essa etimologia sugere que a ação de inventar é um movimento do exterior ao interior, é um deslocamento que vem de fora para dentro, e que tem mais a ver com a sensibilidade ou atenção de um sujeito em relação a seu fora do que com uma ação impulsionada pelo indivíduo desde si mesmo em relação ao fora. Justamente, Simón Rodríguez está muito preocupado com os efeitos da educação para a relação entre as pessoas, nos laços sociais e, a partir disso, concebe a arte de ensinar como um trabalho $\begin{array}{llllll}\text { (c) ETD- Educação Temática Digital } & \text { Campinas, SP } & \text { v.19 } & \text { n.4 } & \text { p. 590-606 } & \text { out./dez. } 2017\end{array}$ 
sobre a atenção do aluno: "a arte de ensinar, que consiste em... saber CHAMAR, CAPTAR e FIXAR a ATENÇÃO" (RODRÍGUEZ, 2001, II, p. 17, destaque do autor), esta que é "uma e indivisível" (RODRÍGUEZ, 2001, I, p. 406). Ou seja, não se trata de promover alunos inventivos no sentido de máquinas de se adequar a novas situações ou de resolver por si mesmos e de forma criativa problemas sempre colocados desde o exterior, mas de formar pessoas inventivamente atentas, sensíveis ao fora, ao exterior, ao comum, à res pública, e que sejam capazes de pensar os modos possíveis, individual e socialmente, de habitar o mundo.

Certamente, a invenção tem também em Simón Rodríguez o valor da não cópia, da não imitação. Isso interessa particularmente no labor pedagógico, que não é técnico, mas artístico. Por isso, a crítica sistemática de Rodríguez à importação de métodos ou técnicas instrutoras mecânicas, como o ensino mútuo de Lancaster (RODRÍGUEZ, 2016, p. 106). Não poderia ser mais claro e mais sintônico nesse sentido $M$. Serres, no belo ensaio inventivo, $O$ terceiro instruído (SERRES, 1991), do qual tomamos a epígrafe desta seção: a falta de invenção em educação é sinônimo de falta de inteligência, cópia, preguiça, convenção, sono, falta de pensamento, besteira, ausência de obra, morte. A invenção é a marca de uma educação reflexiva, no e do pensamento e, sobretudo, vital: a vida inventada na escola é a marca da vitalidade da escola transitada.

\title{
CONSIDERAÇÕES FINAIS: A ESCOLA: A PESQUISA, O MUNDO E VIDA EDUCACIONAIS
}

\begin{abstract}
Nenhuma aprendizagem evita a viagem. Sob a condução de um guia, a educação puxa ao exterior. Parto: salgo. Sais do ventre da tua mãe, do berço, da sombra trazida pela casa do pai e as paisagens juvenis. Ao vento, à chuva: fora faltam os abrigos. Tuas ideias iniciais apenas repetem palavras antigas. Jovem: velho papagaio. A viagem das crianças; eis o sentido desnudo da palavra grega pedagogia. Aprender lança a errância. (SERRES, 1991, p. 27).
\end{abstract}

Um dos efeitos principais do livro de J. Masschelein e M. Simons é operar como uma espécie de despertador. Com efeito, é como se ele nos lembrasse que por trás de tanto aparelho ideológico do Estado, de tanto poder disciplinar e controlador, de tanto vigiar e punir institucionalizados, de tantos dispositivos de governamentalidade, esquecemos que a escola também tem uma forma afirmativa, uma espécie de alma, um espaço tempo específico no qual é possível uma série de operações concretas, que é preciso entender, e das quais importa tirar toda a potência que esse espaço tempo é capaz de propiciar. Esquecemos da singularidade do escolar enquanto escolar, nada menos que do que faz da escola uma escola: o exercício de práticas afirmativas de estudo e experiência com determinadas características singulares, específicas, únicas, para além ou para aquém de tudo que conforma as instituições escolares que habitamos.

\begin{tabular}{|c|c|}
\hline (C) ETD- Educação Temática Digital & \\
\hline
\end{tabular}


Podemos discutir muitos aspectos dessa proposta. Por exemplo, se a crítica à politização da escola não exigiria um tratamento mais explícito e preciso das relações entre escola e política; ou então, qual é o preço que se paga quando se deixa o social, o cultural e histórico do lado de fora do escolar? Ou também: qual é o estatuto epistemológico dessa forma escolar, skholé? Ela é ciência? Literatura? Arte? E qual é seu caráter ontológico? Ela é uma essência? Ela é universal? Trans-histórica? Transcultural? Para ter essa pretensão, ela não deveria considerar outras formas do escolar em outras culturas que não a dominante no Ocidente? Poder-se-ia também questionar se é conveniente ou ainda possível uma análise como a pretendida, estrita e unicamente pedagógica, isolando o escolar de suas dimensões filosófica, histórica, social, cultural, política. Conseguem os autores belgas de fato oferecer uma análise (apenas) pedagógica da escola como pretendem? Enfim, as perguntas poderiam continuar, e elas são também uma amostra da potência do livro de Masschelein e Simons e o que ele tem desencadeado.

Contudo, é importante destacar que o livro Em defesa da escola é apenas uma instância de um projeto mais amplo dos autores belgas de renovar o campo da pedagogia e o modo de entender e praticar a docência e a pesquisa universitárias e, diria de modo mais amplo, um modo de exercer uma vida pedagógica. Não se trata, portanto, apenas da defesa teórica de um conceito ou categoria abstrata, nem da revelação de uma suposta verdade pedagógica, mas de uma análise emergente de uma forma de entender e praticar a pesquisa pedagógica que tem como base o Laboratorium voor Educatie en samenleving na Katholieke Universiteit Leuven (KULeuven), que trata, sobretudo, de inventar escola, de fazer a escola como skholé, ou seja, de parar um pouco o tempo vertiginoso da produtividade acadêmica à qual vida universitária é submetida para experimentar, nela, algo de tempo livre.

Assim, durante os últimos quinze anos, Masschelein realiza sistematicamente com cada turma de alunos do primeiro ano do mestrado em Ciências da Educação da KULeuven viagens pedagógicas, nas quais exercita e coloca à prova suas ideias sobre a escola e a pedagogia, sua "pedagogia pobre" (MASSCHELEIN; SIMONS, 2014). As viagens levam Masschelein e seus alunos da disciplina do Mestrado a um lugar distinto a cada ano, cidades pós-conflitos ou em crises como Kinshasa, Tirana, Saravejo, Belgrado, Bucareste, Atenas, Bruxelas, megalópoles não turísticas na China (Shenzhen e Chongqing), cidades pequenas de aparência banal (St-Claude, Genk) e, mais recentemente, em linhas de ônibus ao leste europeu e em barco em torno do Pinhão de Gibraltar. Em 2012, como parte dessa prática, Masschelein esteve dez dias na Universidade do Estado do Rio de Janeiro com mais de trinta alunos que, junto a outros trinta alunos brasileiros, caminharam pela cidade em busca de skholé. ${ }^{5}$ Não entraremos aqui no detalhe desses exercícios (cf. KOHAN; MARTINS; VARGAS,

\footnotetext{
${ }^{5}$ Uma narrativa coletiva dessa experiência encontra-se em KOHAN; MARTINS; VARGAS, 2013.
}

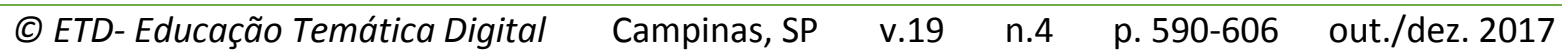


2013), mas queremos afirmar que essas viagens, essas experiências de deslocamento, são exercícios formadores de si na busca de escola e de mundo. Nas palavras de Masschelein, trata-se de uma "educação formadora de mundo" (MASSCHELEIN, 2013a, p. 259) aquela que afasta os estudantes das perspectivas "críticas", distantes e pessoais, para submergi-los em práticas para tornar o mundo verdadeiro ou real, para "estar presente no presente" (MASSCHELEIN, 2013, p. 262), através de exercícios de caminhar e percorrer a cidade mediante linhas traçadas pelo pedagogo, cuja função principal é traçar as linhas e manter atentos, nelas, os caminhantes.

Nessa visão, a pesquisa em pedagogia comporta três marcas específicas: a) ela trata um problema educacional; b) ela torna algo público; c) ela provoca uma mudança no pesquisador (MASSCHELEIN; SIMONS, 2014). Nessa concepção, as referências mais importantes continuam sendo Rancière, Arendt e Foucault. Rancière, porque o pedagogo faz o trabalho e as perguntas de Jacotot ("O que você viu? O que você ouviu? O que você pensa disso? O que você conclui disso? ", MASSCHELEIN, 2013a, p. 259); Arendt, porque se trata de "exercícios de pensamento" preocupados com o presente e com nossa presença no presente, ou seja, com não se esquecer de si mesmo na fenda do tempo, entre o passado e o futuro. (Masschelein, 2014, p. 10-12); por último, Foucault, porque se trata de exercícios de autoformação e autoeducação, que procuram transformar ou modificar o modo de ser de alguém e como esse alguém vive no presente, "um ethos atento e experimental que inclui o uso público da razão, e que, portanto, deve ser concebido como um gesto público". (MASSCHELEIN, 2014, p. 9).

"Ponhamo-nos a caminho" é o título de um dos textos em que Masschelein e Simons (2014) apresentam essa tentativa, mas também é um chamado, um convite, uma convocação a sair do lugar, a abandonar a comodidade, a se expor ao mundo. Ali os pedagogos belgas afirmam: "O importante, ao caminhar, é pôr em movimento esse sujeito e essa posição. Caminhar é uma ex-posição, um estar fora da posição". (MASSCHELEIN; SIMONS, 2014, p. 41). Por isso, repetimos, é preciso sair do lugar, se ex-por à autoridade do caminho, confiar mais na atenção que nas intenções, abrir-se para o mundo, estar atento e aberto ao mundo. Tratar-se-ia de excursões, ex-coursos, cursos indo fora de si mesmos. (MASSCHELEIN, 2016).

Em uma direção aparentemente oposta, mas com objetivos compartilhados, o parceiro de Masschelein, Maarten Simons desenvolve um projeto, Universita Studii, no mesmo Laboratório da KULeuven, onde a Universidade, para desempenhar seu papel público como Universidade, não se concentra em levar seus estudos e estudantes para fora, mas em convidar alguns praticantes de diferentes áreas à universidade para recuperar um espaço e um tempo para estudar e tornar-se novamente estudantes. O objetivo é inverter o

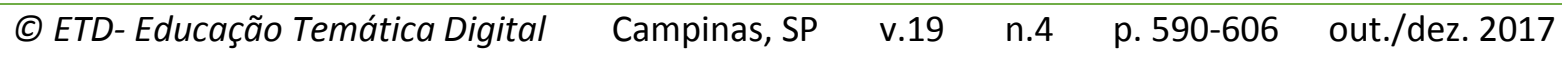


mote de levar a teoria à prática em um que dê à prática a chance de se tornar teórica. Através deste projeto, estudantes regulares e praticantes "externos" compartilham uma preocupação pelo que importa e uma experiência mais demorada do tempo.

Neste breve texto, tentamos oferecer alguns elementos para melhor compreender a tentativa dos autores belgas e também nos propusemos a oferecer certos aspectos de um outro pensamento sobre a escola e o escolar advindo da tradição da escola popular latinoamericana. Apresentamos assim o mestre Simón Rodríguez, basicamente no que diz respeito à invenção, a partir da sua invenção de uma escola popular em Chuquisaca, Bolívia, na primeira parte do século XIX. A partir dela, propomos a invenção, no sentido da atenção e da hospitalidade em relação ao que está fora, e aos que estão marginados, excluídos, como um outro componente "inesquecível" da escola e do escolar, pelo menos entre nós, na América Latina. Assim, sua forma de inventar escola ensina uma forma de a escola abrir as suas portas ao outro, ao desprezado, ao desatendido, ao desconsiderado, como um igual, ou seja, sem condições. Essa forma diz respeito não apenas a quem ensina, mas a quem aprende, e também marca de maneira expressiva a própria atividade escolar, o escolar enquanto escolar, para dizê-lo nos termos expressos por Masschelein e Simons.

Para finalizar, queremos chamar a atenção sobre mais uma característica da escola presente também nessa tradição em que se encontra Simón Rodríguez e que está também muito presente na forma de Masschelein e Simons entendem e praticam a pesquisa pedagógica, segundo acabamos de apresentá-la. Também um estrangeiro a essa tradição, como Michel Serres, destaca ela tão nitidamente no texto que serve de epígrafe a esta última seção. A escola popular de Chuquisaca, tal como a apresentamos na seção anterior, foi demolida pelos que a consideravam uma ameaça à ordem imperante. Ela era a tarefa de um louco, estrangeiro, delirante. Perante a demolição de sua escola, Simón Rodríguez não ficou quieto: continuou fazendo escola viajando, passou os últimos vinte e tantos anos de sua vida errando, fazendo escola, buscando escola, inventando escola.

Simón Rodríguez repetia muitas vezes "inventamos ou erramos" (RODRÍGUEZ, 2016). Considerava a América terra da invenção. Uma forma literal de entender essa frase é através da oposição entre invenção e imitação/erro: assim, ela estaria afirmando que, se não inventarmos, ou seja, se imitarmos, se copiarmos, estaríamos errando, no sentido em que a invenção seria a única forma de nos afastar do erro. Segundo esta interpretação, inventar, no sentido de não copiar, seria a forma de não errar, que teria o sentido de equivocar-se. Para não se equivocar, seria necessário inventar, não imitar.

Contudo, errar pode querer dizer também viajar, vagar, deambular sem uma destinação fixa, atento aos sentidos que emanam da própria viagem. O errante é quem sai sem destino fixo, não sem destino, mas sem um destino que não seja encontrado na própria

\begin{tabular}{|c|c|}
\hline (c) ETD- Educação Temática Digital & \\
\hline
\end{tabular}


viagem. O errante é alguém atento aos sentidos emanados da própria viagem. A conjunção "ou" pode também ter outro sentido além do disjuntivo: ela pode não estar contrapondo dois termos como alternativas excludentes, senão mostrando o segundo como uma equivalência ou uma instância do primeiro, como quando dizemos "é um quilômetro ou mil metros". Assim "inventamos ou erramos" pode querer também dizer que a errância é uma forma equivalente da invenção, ou seja, que através da errância se inventa. Em certo sentido, a vida de Rodríguez mostra isso: uma vida errante que inventa escola, que faz da invenção um modo de fazer escola: errando, inventamos. Ou seja, "inventamos ou erramos", pode também querer dizer "inventamos, isto é, erramos" ou "Errando inventamos".

Serres parece pressupor essa mesma relação no seu inspirador e sedutor Le TeirsInstruit (1991). Coloca a viagem como uma condição da aprendizagem na epígrafe desta seção: não há aprendizagem sem viagem. Não se trata de qualquer viagem: não há aprendizagem sem essa condição de desabrigo a que de alguma forma nos submetemos cada vez que erramos, quando nos colocamos a caminho de pôr em questão alguma coisa, de questionarmo-nos sobre o que a vida nos chama a nos questionar. Serres o diz de maneira emocionante: a aprendizagem lança a errância. Ou, como o próprio Serres o manifesta naquele texto inicial que serve de epígrafe no primeiro início de nosso texto e que, na sequência do seu livro, segue àquele parágrafo que prefacia à presente seção: a aprendizagem comporta uma sorte de explosão em pedaços, ela bifurca o que é colocado como natural e conduz a um lugar ignorado por um caminho desconhecido e incômodo. Aprender desacomoda, inquieta, comove, desassossega, impressiona, preocupa, incomoda.

Não estamos apenas listando mais uma (s) característica (s) do escolar que estaria (m) faltando na análise dos autores belgas aqui estudados. Estamos afirmando um modo de nos relacionar com o outro, com as outras ideias, com as outras escolas, com as outras vidas. Pode ser um pensamento, um livro, um prédio, um caminho, uma pergunta, uma escola, um ser humano. Trata-se do outro, do estranho, do estrangeiro. O movimento que gera a presença do outro, no pensamento e na vida, é sempre desestabilizador, comovente, inquietante. É também o motor para que o mundo possa ser (visto, pensado e vivido) de outra maneira.

Não há como aprender desde a comodidade, o conforto, a estabilidade. Estamos já perto do final e estava esquecendo de outra palavra mencionada por Serres. A explosão e a incerteza comportadas pela aprendizagem exigem um heroísmo tal que apenas um espírito infantil parece capaz de lançar-se nesse caminho, afirma o francês. O escolar é a terra da infância. Mas a comoção e a incerteza do caminho são tais que a infância por si só não empreenderia o caminho: é preciso ainda seduzi-la. Seduzi-la, ou seja, conduzir a infância a

\begin{tabular}{|c|c|}
\hline (C) ETD- Educação Temática Digital & \\
\hline
\end{tabular}


outra parte. Espero, sinceramente, que este texto tenha conduzido os seus leitores, que ainda habitam a infância, à algumas outras partes do escolar. E, quem sabe, a outras partes do mundo. E da vida.

\section{REFERÊNCIAS}

ARENDT, Hannah. The Crisis in Education (1958). In: ARENDT, H. Between past and future: eight exercises in political thought. New York: Penguin, 1977.

DURÁN, Maximiliano. Simón Rodríguez. Una filosofía de la radical novedad. Caracas: Ediciones del Solar, 2016.

FOUCAULT, Michel. A hermenéutica do sujeito. São Paulo, SP: Martins Fontes, 2006.

KOHAN, Walter. O mestre inventor. Simón Rodríguez. Belo Horizonte, MG: Autêntica, 2013.

KOHAN, Walter; MARTINS, Fabiana; VARGAS, Maria Jacintha (Org.). Encontrar escola: o ato educativo e a experiência da pesquisa em educação. Rio de Janeiro, RJ: Lamparina, 2013.

KOHAN, Walter; MASSCHELEIN, Jan. Filosofia como (auto) educação: para fazer a voz do pedagogo ser ouvida. In: MASSCHELEIN, Jan; SIMONS, Maarten. A pedagogía, a democracia, a escola. Belo Horizonte, MG: Autêntica, 2014. p. 197-235.

LIDDELL, Henry G., SCOTT, Robert. A greek english lexicon. Oxford: Clarendon, 1958. New Edition by Henry Stuart Jones, 1966.

MASSCHELEIN, Jan. O mundo mais uma vez. Andando sobre linhas. In: KOHAN, Walter; MARTINS, Fabiana; VARGAS, Maria Jacintha (Org.). Encontrar escola: o ato educativo e a experiência da pesquisa em educação. Rio de Janeiro, RJ: Lamparina, 2013. p. 259-264.

MASSCHELEIN, Jan. Filosofia como (auto)educação: para fazer a voz do pedagogo ser ouvida. In: MASSCHELEIN, Jan; SIMONS, Maarten. A democracia, a pedagogia, a escola. Belo Horizonte, BH: Autêntica, 2014. p. 7-24.

MASSCHELEIN, Jan; SIMONS, Maarten. Em defesa da escola. Belo Horizonte, MG: Autêntica, 2013.

MASSCHELEIN, Jan; SIMONS, Maarten. A democracia, a pedagogia, a escola. Belo Horizonte, MG: Autêntica, 2014.

MASSCHELEIN, Jan; SIMONS, Maarten. The language of the school: alienating or emancipating? In: KOHAN, Walter; LOPES, Sammy; MARTINS, Fabiana (Org.) 0 ator de educar em uma língua ainda por ser escrita. Rio de Janeiro, RJ: NEFI, 2106. p. 291-300.

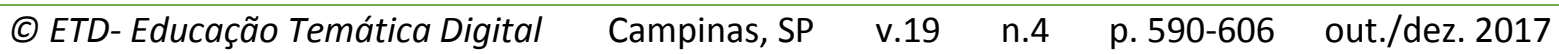


PUIGGRÓS, Adriana. De Simón Rodríguez a Paulo Freire. Educación para la integración latinoamericana. Buenos Aires: Colihue, 2005.

RANCIÈRE, Jacques. Le maître ignorant. Paris: Fayard, 1987. Trad. Port. O mestre ignorante. Belo Horizonte, MG: Autêntica, 2002.

RANCIÈRE, Jacques. Ecole, production, égalité. In: L'école de la démocratie. Edilig: Fondation Diderot, 1988.

RODRÍGUEZ, Simón. Obras completas. Caracas: Presidencia de la República Bolivariana de Venezuela, 2001.

RODRÍGUEZ, Simón. Inventamos ou erramos. Belo Horizonte, MG: Autêntica, 2016.

SERRES, Michel. Le tiers-Instruit. Paris: François Bourin, 1991.

SIMONS, Maarten; MASSCHELEIN, Jan. School experiences: an attempt to find a pedagogical voice. In: KOHAN, Walter; LOPES, Sammy; MARTINS, Fabiana (orgs.) 0 ator de educar em uma língua ainda por ser escrita. Rio de Janeiro, RJ: NEFI, 2016. p. 249-258.

' Revisão gramatical do texto sob a responsabilidade dos autores 